\section{Prevalence of blindness in children}

Childhood blindness carries a high financial cost for the community as well as a high individual cost impacting normal motor, language and social development of the child. These factors are all compounded when the child enters the education system and adulthood. There are very little accurate data available on the prevalence of blindness in children.
We have recently published the results of a capture and recapture estimate of the total blind population in Western Australia. This estimate was derived from three independent lists of legally blind people and is a well-validated method for the accurate determination of population sizes. ${ }^{2}$ Here, we add additional analysis of a subset of data on the children contained within the original capture and recapture lists to provide an estimate of the prevalence of blindness in those aged less than 18 years.

Blind children were identified either from the voluntary register of the Association for the Blind of Western Australia (list A) or from paediatric ophthalmologists' clinics (list B). The cohort was defined as being legally blind on or before 30 September 2009 and born after 30 September 1991. Legal blindness was defined as having a best corrected visual acuity of Log minimum angle of resolution (MAR) $>1$ or $<10^{\circ}$ diameter of visual field or a combination of both reduced visual acuity and field restriction, resulting in an equivalent level of vision loss, in the better eye. Also included were children whose clinical features were consistent with blindness (cannot fix or follow light) but whose acuity could not be measured.

We used the methods prescribed by Regal and $\mathrm{Hook}^{3}$ to estimate the population size of children who are blind (N) using two independent lists:

$$
\widehat{N}=\frac{X_{+1} X_{1+}}{X_{11}}
$$

where $X_{11}$ was the number of children identified on both lists $A$ and $B, X_{1+}$ was cases identified only by list $A$ and $X_{+1}$ was cases only on list $B$. The data are shown in an incomplete $2 \times 2$ contingency table (table 1). The $\widehat{\mathrm{SE}}$ of $\widehat{\mathrm{N}}$ is given by

$$
\widehat{\mathrm{SE}}(\widehat{\mathrm{N}})=\left(\frac{\mathrm{X}_{+1} \mathrm{X}_{1+} \mathrm{X}_{12} \mathrm{X}_{21}}{\mathrm{X}_{11}^{3}}\right)^{1 / 2}
$$

An approximate $95 \%$ SE-based interval is given by

$$
\widehat{\mathrm{N}} \pm 1.96 \widehat{\mathrm{SE}}(\widehat{\mathrm{N}})
$$

Using this prescribed method, the estimated population of children who were blind in WA was calculated to be $110(95 \% \mathrm{Cl} 81$ to

Table 2 Incomplete contingency table containing the numbers of blind children obtained in two lists

\begin{tabular}{lllll}
\hline & & \multicolumn{2}{c}{ List B } & \\
\cline { 3 - 5 } & & Present & Absent & Total \\
\hline \multirow{2}{*}{ List A } & Present & 6 & 54 & 60 \\
& Absent & 5 & - & \\
& Total & 11 & & \\
\hline
\end{tabular}

139). This represented a prevalence of $0.02 \%$ of the population aged less than 18 years in $2009 .{ }^{4}$ The whole population prevalence of blindness was previously estimated to be $0.15 \%$ and when age restricted to those aged more than 50 years was $0.43 \%{ }^{1}$

This calculated estimate of the prevalence of blindness in children was broadly consistent with that of WHO where blindness was defined as having a visual acuity of Log MAR $>1.3$, and children defined as aged 0 15 years. WHO estimated the prevalence of child blindness as $0.03 \%$ of the population in developed countries. ${ }^{5}$

This population estimate was made using two rather than three lists due to the low numbers of blind children (table 2). No children were present on all three of the original lists and therefore the $\mathrm{CI}$ resulting from such three-list calculations would have been unreasonable. By using two overlapping and independent lists we have obtained an accurate estimate of the population size, in line with WHO estimates and other published estimates. ${ }^{6}$ Less than half of the children who were legally blind were registered to receive rehabilitation and support services from the state provider.

Julie Mary Crewe, ${ }^{1}$ Nigel Morlet, ${ }^{1}$ Geoff Lam, ${ }^{2}$ James Bernard Semmens'

'Centre for Population Health Research, Curtin Health Innovation Research Institute, Curtin University, Perth, Western Australia, Australia; ${ }^{2}$ School of Paediatrics and Child Heatth, University of Western Australia, Perth, Western Australia, Australia

Correspondence to Julie Mary Crewe, Centre for Population Health Research, Curtin Health Innovation Research Institute, Curtin University, GPO 80x U1987, Perth, WA 6845, Australia; j.crewe@cuttin.edu.au

Acknowledgements We acknowledge the blind and vision impaired members, the support staff and Dr Margaret Crowley of the Association for the Blind of Western Australia. All members of EVER group who assisted with the design of the study: Wiliam Morgan, Antony Clark and Jonathon $\mathrm{Ng}$ as clinical ophthaimologists assisted with patient recruitment and data collection. Antony Clark and Katrina Spilsbury assisted with statistical analysis. Aqif Mukhtar provided technical support and Margaret Crowley was data custodian of the blind register database.

Table 1 Incomplete contingency table

\begin{tabular}{lllll}
\hline & & List B & & \\
\cline { 3 - 4 } & & Present & Absent & Total \\
\hline List A & Present & $X_{11}$ & $X_{12}$ & $X_{1+}$ \\
& Absent & $X_{21}$ & - & \\
& Total & $X_{+1}$ & & \\
\hline
\end{tabular}

Contributors The following are members of EVER (Eye and Vision Epidemiology Research) group: JC (project coordinator), JS (chief investigator), NM and GL (consultant ophthalmologists). JC carried out data collection for the trial, performed statistical analysis, cleaned and analysed the data, and drafted and revised 
the paper. She is the guarantor. NM initiated the collaborative project, provided conception of study design, analysed the data, and drafted and revised the paper. GL critically reviewed the data and manuscript. providing significant intellectual and critical comments. JS critically reviewed the manuscript and provided approval of the final manuscript for submission for publication.

Funding This project was generously supported by an unconditional grant from The Eye Surgery Foundation, Perth, Western Australia.

Competing interests None.

Ethics approval Curtin University Human Research Ethics Committee.
Provenance and peer review Not commissioned; internally peer reviewed.

Published Online First 4 October 2012

Br J Ophthalmol 2012:96:1537-1538.

doi:10.1136/bjophthalmol-2012-302563

\section{REFERENCES}

1. Crewe J, Morgan Wh, Mortet N, et al. Prevalence of blindness in Western Australia: a population study using capture and recapture techniques. $B r J$ Ophthaimol 2012;96:478-81.
2. Hook EB, Regal RR. Capture-recapture methods in epidemialogy: methods and limitations. Epidemiol Rev 1995:17:243-64.

3. Regal RR, Hook EB. Goodness-offit based confidence intervals for estimates of the size of a closed population. Stat Med 1984;3:287-91.

4. Australian Bureau of Statistics. Report 2010.

5. World Health Organization. Preventing blindness in children. Report of a WHO/APB scientific meeting. Geneva; 2000 WHO/PBL/00.77.

6. Gilbert CE, Anderton L, Dandona L, et al. Prevalence of visual impairment in children: a review of available data. Ophthalmic Epidemiol 1999;6:73-82. 